\title{
DFT study on hydrogen-bonding adsorption mechanism of rutin onto macroporous adsorption resins functionalized with amino, hydroxyl, and carboxyl groups
}

\author{
He-lin Ye $\cdot$ Yong-feng Liu $\cdot$ Xing-hui Zhang $\cdot$ \\ Duo-long Di
}

Received: 22 August 2012/ Accepted: 21 November 2012/Published online: 7 December 2012

(C) The Author(s) 2012. This article is published with open access at Springerlink.com

\begin{abstract}
The adsorption mechanism of a series of macroporous adsorption resins $\left(p-\left(\mathrm{CH}_{3} \mathrm{NH}\right) \mathrm{PhL}\left(\mathrm{L}=\mathrm{NH}_{2}\right.\right.$, $\mathrm{OH}, \mathrm{COOH})$ ) with rutin have been investigated using density functional theory calculations at B3LYP/6$31 \mathrm{G}(\mathrm{d}, \mathrm{p})$ level of theory. Solvent effects on these species were explored using calculations that included a polarizable continuum model for the aqueous solvent. In this article, the geometry structure, interaction energies and the infrared spectra for the stable reactants and the adsorption complexes were obtained and analyzed. The results show that the hydrogen-bonding have been formed in the adsorption complexes. The higher interaction energy is calculated for the carboxyl group, while the resin with amino group has the highest adsorption capacity for rutin. The adsorption complexes become more and more stable as increasing the number of adsorbents. Our theoretical study is in good explanation for the experimental results.
\end{abstract}

Keywords Macroporous adsorption resins - Rutin · Hydrogen-bonding adsorption · Density functional theory

H. Ye · Y. Liu · D. Di (ه)

Key Laboratory of Chemistry of Northwestern Plant Resources and Key Laboratory for Natural Medicine of Gansu Province, Lanzhou Institute of Chemical Physics, Chinese Academy of Sciences, Lanzhou 730000, People's Republic of China e-mail: didl@licp.cas.cn

H. Ye $\cdot$ Y. Liu

Graduate University of the Chinese Academy of Sciences, Beijing 100049, People's Republic of China

X. Zhang

College of Chemical Engineering, Gansu Lianhe University, Lanzhou 730010, People's Republic of China

\section{Introduction}

Macroporous adsorption resins (MARs) are synthetic porous crosslinked polymer beads, have been developed into a kind of novel functional materials since 1950. They have been shown to be potentially powerful separation materials and have been widely applied in many fields, such as chromatographic analysis [1], treatment [2], pharmaceutical [3], food industries, and wastewater disposal [4]. Except for the general advantage of that of the common adsorbent, MARs possess many special characteristics such as high mechanical strength, good acid and alkali resistance, porous availability, high surface area, and a long lifetime that make them more promising [5-7]. To gain a greater adsorption capacity and a higher adsorption selectivity for some specific organic compounds, chemical modification of MARs is often undertaken by introducing special functional groups into the matrix of the polymeric adsorbents $[8,9]$. Thus, investigation on the adsorption features of organic compounds on MARs is of great importance $[10,11]$. However, theoretical research on the adsorption features of MARs lags far behind. Although there are several reports about the adsorption feature of MARs, and many of adsorption systems have been observed to exhibit multiphasic behavior [12-14]. But little has been done to determine the impacts of the pore size distribution and the functional groups of polymer resins. To the best of our knowledge, there are no detailed theoretical studies available on hydrogen-bonding adsorption mechanism of rutin onto MARs by density functional method.

Recently, we have experimentally synthesized a series of adsorption MARs with hydrogen-bonding groups, which were amino, hydroxyl, and carboxyl groups, respectively (Scheme 1). Adsorption feature of the synthetic resins with respect to the purification effect was investigated systemically 
Scheme 1 The preparation method for macroporous adsorption resins modified with amino benzene compounds

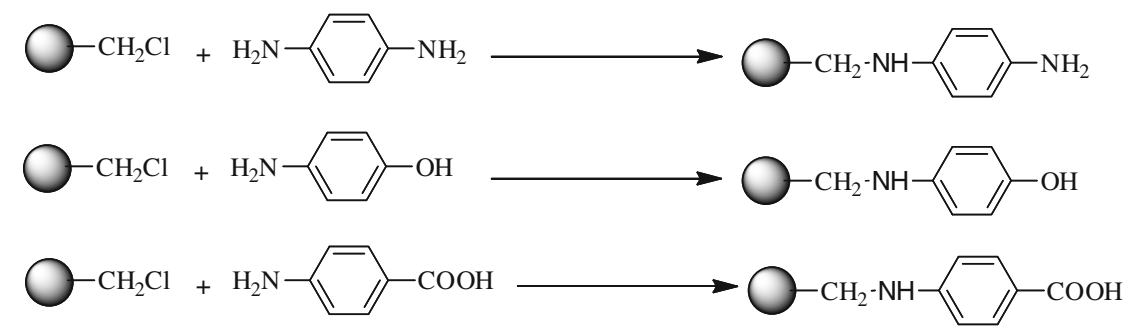

by employing rutin as the adsorbate. The experimental results showed that MARs with amino group have the higher adsorption capacity and the adsorption selectivity. In this article, we present a hybrid DFT(B3LYP) study for the adsorption mechanism of rutin onto MARs functionalized with amino, hydroxyl, and carboxyl groups. The MARs are the molecule of $p$ - $\left(\mathrm{CH}_{3} \mathrm{NH}\right) \mathrm{PhL}\left(\mathrm{L}=\mathrm{NH}_{2}, \mathrm{OH}, \mathrm{COOH}\right)$ as model system. With this theoretical study, we hope to obtain a detailed understanding of adsorption mechanism and predict the trends of adsorption capacity for MARs with the different groups. Meanwhile, we expect to find out more about the factors that control the interaction energies of this important reaction and further investigate the effects of solvent of the reaction systems.

\section{Computational methods}

All of the geometries of the model complexes were fully optimized using the density functional theory (DFT) method based on the hybrid of Becke's three-parameter exchange functional and the Lee, Yang, and Parr correlation functional (B3LYP) [15, 16]. The 6-31G basis set $[17,18]$ with polarization (d) and (p) was used for all of the atoms. Frequency calculations at the same level of theory have been achieved to identify each optimized stationary point as either minima (the number of imaginary frequencies $[\mathrm{NIMAG}=0]$ ) and to evaluate the zero-point energy (ZPE) corrections, which are included in all relative energies. The thermodynamic functions, including free energies, were calculated at $298.15 \mathrm{~K}$ and $1 \mathrm{~atm}$. In consideration of the solvent effects on the reactions of interest, we applied a continuum medium to do the full geometry solvation energy calculations for all of the species, using UAHF radii on the polarizable continuum model (PCM). The PCM calculations [19-21] were done at the B3LYP/ PCM/6-31G(d,p) level of theory. $\mathrm{H}_{2} \mathrm{O}$ was used as the solvent, corresponding to the experimental conditions, and the dielectric constant was assumed to be 78.39 for bulk aqueous solution. All calculations reported here have been carried out with Gaussian 03 program package [22].

\section{Results and discussion}

In the first part of this section, we present results from our calculations on the adsorption process of rutin to the different MARs $p$ - $\left(\mathrm{CH}_{3} \mathrm{NH}\right) \mathrm{PhL}\left(\mathrm{L}=\mathrm{NH}_{2}, \mathrm{OH}, \mathrm{COOH}\right)$. The influence of the number of rutin upon the adsorption energies and structures is investigated in the second part. The optimized stationary structures of the reactants and the adsorption complexes are depicted schematically in Figs. 1, 2, and Table 1 with selected key geometry parameters (bond lengths and bond angles). The total energies with ZPE

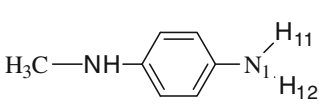

A

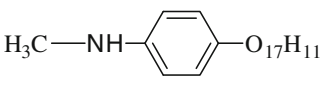

B

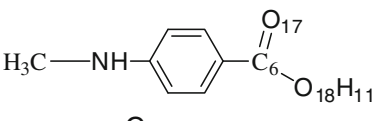

C

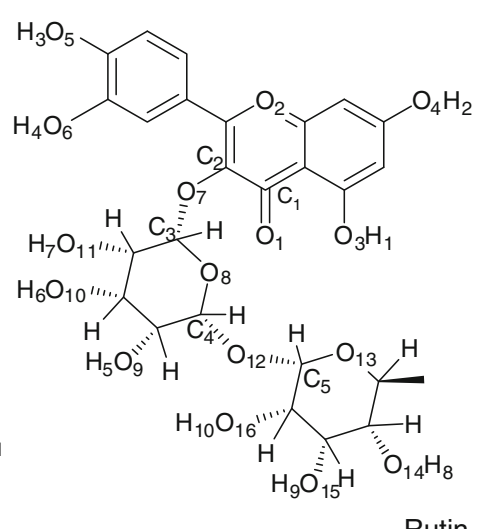

Rutin
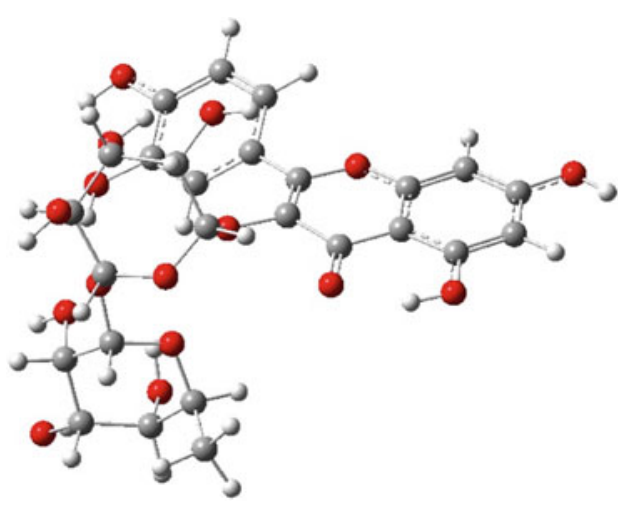

Fig. 1 The structures of $p-\left(\mathrm{CH}_{3} \mathrm{NH}\right) \mathrm{PhL}\left(\mathrm{L}=\mathrm{NH}_{2}, \mathrm{OH}, \mathrm{COOH}\right)$ and the optimized minimum energy geometry of rutin 


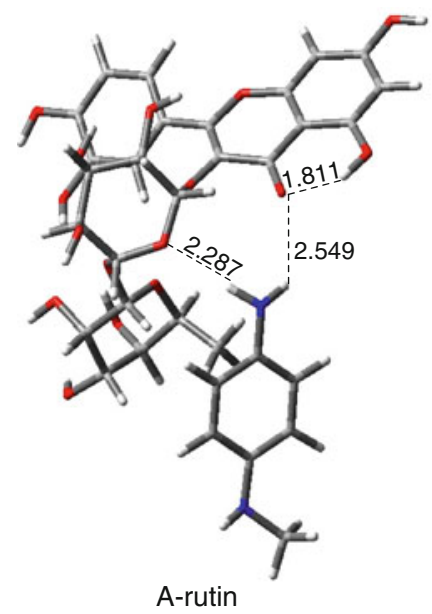

A-rutin

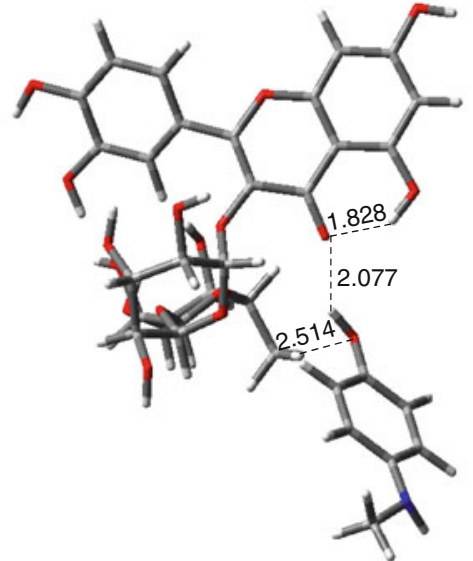

B-rutin

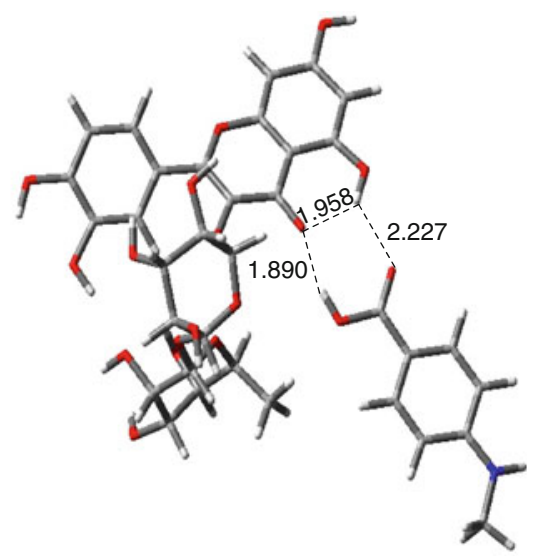

C-rutin

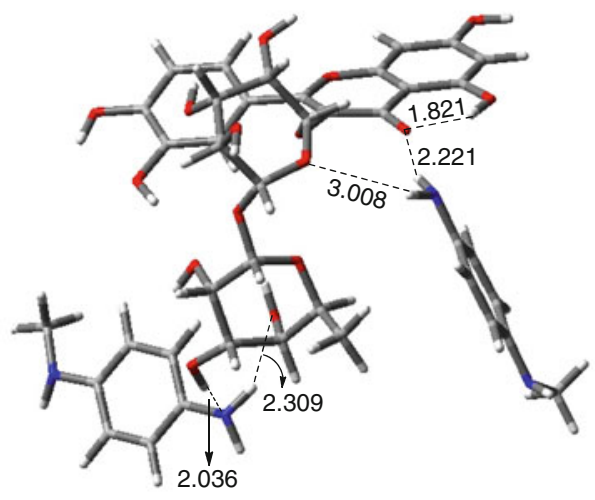

A2-rutin

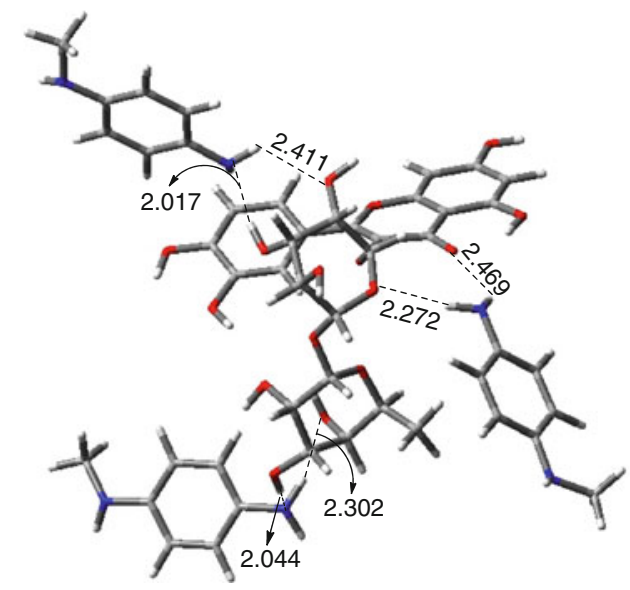

A3-rutin

Fig. 2 The full optimized minimum energy geometries for rutin with A, B, and C, with selected structural parameters (bond lengths in $\AA$ )

corrections and the relative energies to the starting materials are listed in Table 2.

Adsorption mechanism of rutin onto $p-\left(\mathrm{CH}_{3} \mathrm{NH}\right) \mathrm{PhL}$ $\left(\mathrm{L}=\mathrm{NH}_{2}, \mathrm{OH}, \mathrm{COOH}\right)$

Figure 1 shows the optimized geometry of rutin and the structures of $p-\left(\mathrm{CH}_{3} \mathrm{NH}\right) \mathrm{PhL}\left(\mathrm{L}=\mathrm{NH}_{2}, \mathrm{OH}, \mathrm{COOH}\right)$. The main geometry parameters are shown in Table 1 . As one can see from Fig. 1 and Table 1, the C1-O1, O1-H1, and O3-H1 bond lengths in rutin are $1.218,1.804$, and $0.953 \AA$, respectively. The $\mathrm{C} 2-\mathrm{O} 7-\mathrm{C} 3, \mathrm{C} 3-\mathrm{O} 8-\mathrm{C} 4$, and $\mathrm{C} 4-\mathrm{O} 12-\mathrm{C} 5$ bond angles are $121.2^{\circ}, 120.6^{\circ}$, and $117.4^{\circ}$, respectively. The MESP painted on the van der Waals surface is presented in Fig. 3 for the MAR and rutin, which shows strong charge separation in the systems, the oxygen and nitrogen atom are negatively charged while the rest of the molecule (hydrogen and carbon) is positively charged. These pictures also indicate that the $\mathrm{H}$ is donated to the $\mathrm{O}$ and $\mathrm{N}$. The stronger electronegativity of A-C structures was attributed to the largest micropore surface, where rutin can be intensively adsorbed by a micropore filling mechanism. The structures of the adsorption complexes with the most relevant geometry parameters are shown in Fig. 2 and Table 1.

Inspection of Fig. 2 and Table 1 shows that the adsorption process forms the new hydrogen-bonding in the structures of A-rutin, B-rutin, and C-rutin, respectively. The O1-H11 and O8-H12 bond lengths are 2.549 and $2.287 \AA$, respectively, in A-rutin, and the $\mathrm{O} 1-\mathrm{H} 1$ and $\mathrm{C} 4-\mathrm{O} 8$ bond lengths elongated by $0.007 \AA(1.804 \AA$ in rutin) and $0.011 \AA(1.384 \AA$ in rutin), respectively, upon going from the reactants to the adsorption complexes. The similar features of the geometry parameters are also found for B-rutin and C-rutin, and the new hydrogen-bonding of $\mathrm{O} 1-\mathrm{H} 11$ in B-rutin and the O1-H11 and O17-H1 bond distances in C-rutin are 2.077, 1.890 , and $2.227 \AA$ A, respectively. These changes in the bond lengths and angles are attributed to form the more stable adsorption complexes. Meanwhile, Fig. 4 shows the IR 
Table 1 The partial bond length $(\AA)$ and bond angle $\left(^{\circ}\right)$ of rutin, $\mathrm{A}, \mathrm{B}, \mathrm{C}$, and the adsorption complexes at B3LYP/PCM/6-31G(d,p) level

\begin{tabular}{|c|c|c|c|c|c|c|c|}
\hline Parameters & Rutin & A & $\mathrm{B}$ & $\mathrm{C}$ & A-rutin & B-rutin & C-rutin \\
\hline $\mathrm{C} 1-\mathrm{O} 1$ & 1.218 & & & & 1.220 & 1.221 & 1.220 \\
\hline $\mathrm{C} 2-\mathrm{O} 7$ & 1.352 & & & & 1.357 & 1.353 & 1.354 \\
\hline $\mathrm{C} 3-\mathrm{O} 7$ & 1.396 & & & & 1.396 & 1.395 & 1.395 \\
\hline $\mathrm{C} 3-\mathrm{O} 8$ & 1.385 & & & & 1.384 & 1.385 & 1.383 \\
\hline $\mathrm{C} 4-\mathrm{O} 8$ & 1.384 & & & & 1.391 & 1.390 & 1.384 \\
\hline $\mathrm{C} 4-\mathrm{O} 12$ & 1.387 & & & & 1.376 & 1.381 & 1.384 \\
\hline C5-O12 & 1.373 & & & & 1.380 & 1.371 & 1.371 \\
\hline N1-H11 & & 0.995 & & & 0.995 & & \\
\hline N1-H12 & & 0.995 & & & 0.995 & & \\
\hline O17-H11 & & & 0.941 & & & 0.945 & \\
\hline C6-O17 & & & & 1.191 & & & 1.195 \\
\hline C6-O18 & & & & 1.329 & & & 1.318 \\
\hline O18-H11 & & & & 0.942 & & & 0.954 \\
\hline O1-H1 & 1.804 & & & & 1.811 & 1.828 & 1.958 \\
\hline $\mathrm{O} 3-\mathrm{H} 1$ & 0.953 & & & & 0.955 & 0.955 & 0.955 \\
\hline O1-H11 & & & & & 2.549 & 2.077 & 1.890 \\
\hline O8-H12 & & & & & 2.287 & & \\
\hline O17-H1 & & & & & & & 2.227 \\
\hline $\mathrm{C} 2-\mathrm{O} 7-\mathrm{C} 3$ & 121.2 & & & & 121.0 & 120.8 & 120.8 \\
\hline $\mathrm{C} 3-\mathrm{O} 8-\mathrm{C} 4$ & 120.6 & & & & 120.3 & 120.1 & 119.9 \\
\hline $\mathrm{C} 4-\mathrm{O} 12-\mathrm{C} 5$ & 117.4 & & & & 118.7 & 118.9 & 118.5 \\
\hline
\end{tabular}

Table 2 Interaction energies for the macroporous adsorption resin with rutin

\begin{tabular}{|c|c|c|c|c|c|}
\hline System & $E_{\mathrm{ZPE}}$ (a.u.) & $E_{\text {gas }}^{\mathrm{tot}}$ (a.u.) & $\Delta E_{\mathrm{gas}}^{\mathrm{rel}}\left(\mathrm{kcal} \mathrm{mol}^{-1}\right)$ & $E_{\text {sol }}^{\text {tot }}$ (a.u.) & $\Delta E_{\mathrm{sol}}^{\mathrm{rel}}\left(\mathrm{kcal} \mathrm{mol}^{-1}\right)$ \\
\hline A-rutin & 0.764111 & $-2,577.747484$ & -4.32 & $-2,578.602388$ & -8.92 \\
\hline B-rutin & 0.751420 & $-2,597.590740$ & -6.41 & $-2,598.423295$ & -9.75 \\
\hline C-rutin & 0.763164 & $-2,710.355016$ & -7.32 & $-2,711.204647$ & -11.21 \\
\hline A2-rutin & 0.939728 & $-2,957.386925$ & -9.55 & $-2,958.416132$ & -9.95 \\
\hline A3-rutin & 1.109843 & $-3,337.031674$ & -18.10 & $-3,338.238199$ & -10.69 \\
\hline
\end{tabular}

These values were calculated at the B3LYP/6-31G(d,p) level of theory, using the full geometry optimization at the B3LYP/PCM/6-31G(d,p) level of theory to model the effect of water

Total energy $E^{\text {tot }}$, zero-point energy $E_{\mathrm{ZPE}}$, relative energy $\Delta E^{\text {rel }}$
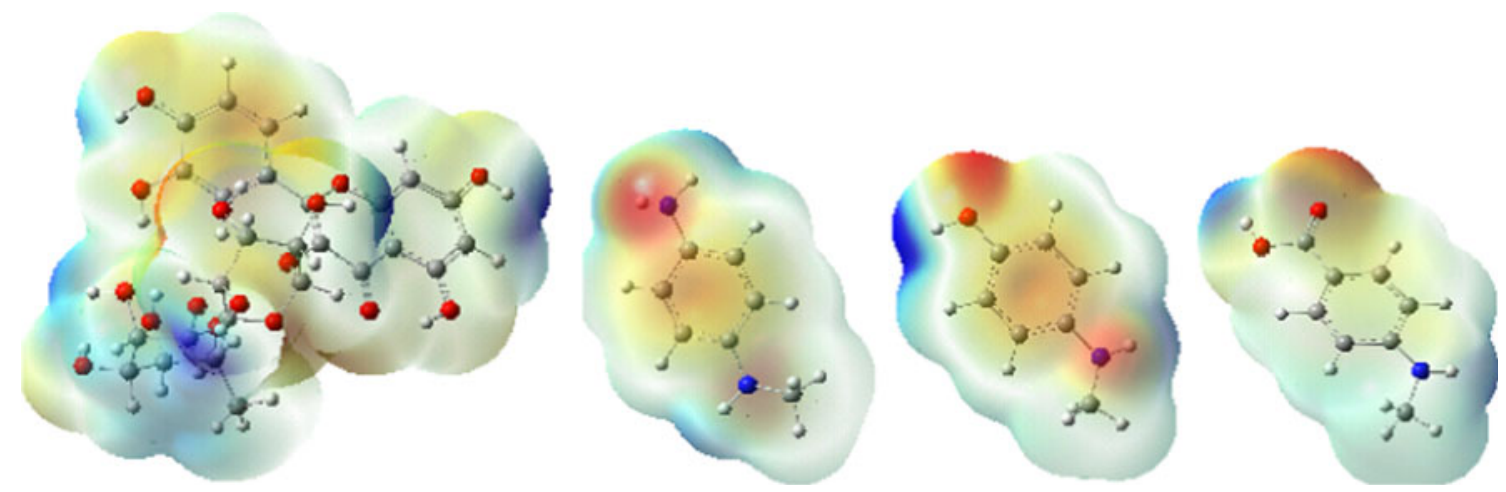

Fig. 3 The electrostatic potential mapped on to the van der Waals surface of a representative set of rutin and the macroporous adsorption resin 


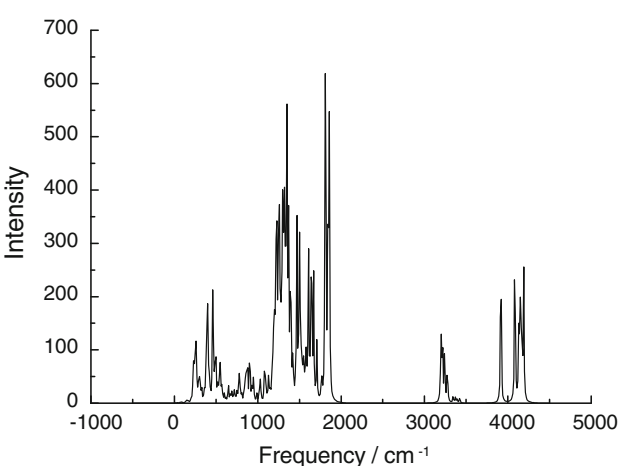

Rutin

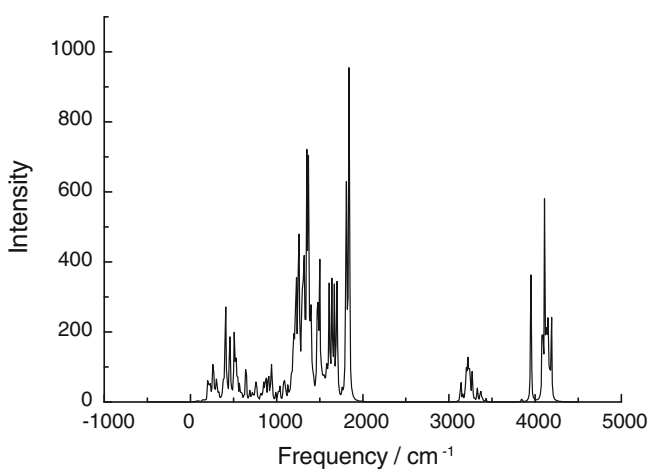

B-rutin

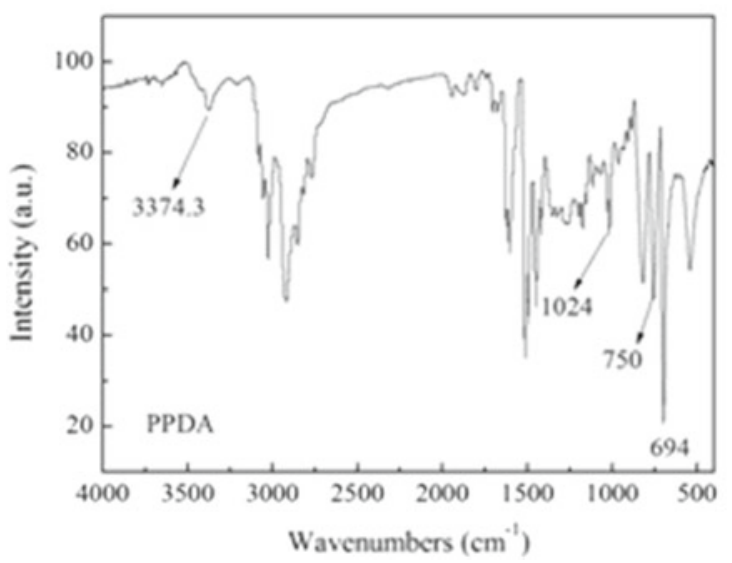

A

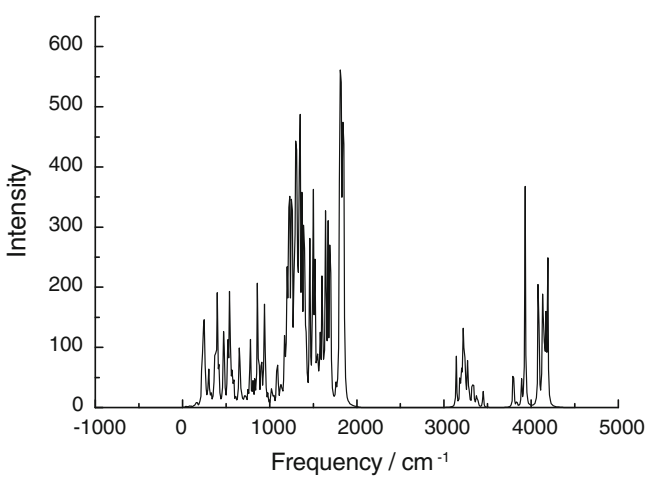

A-rutin

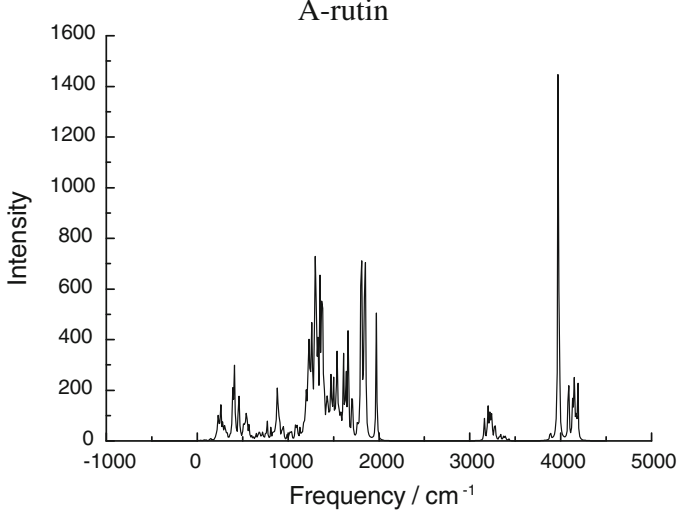

C-rutin

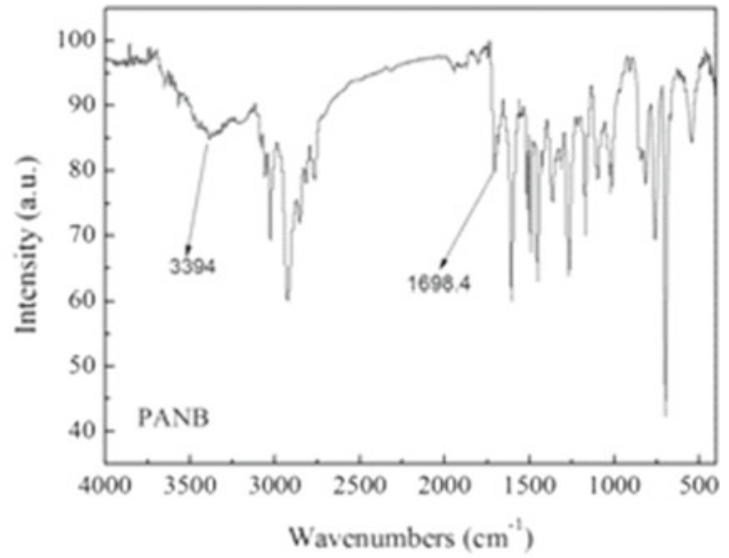

C

Fig. 4 The IR spectrum for the stable rutin, A-rutin, B-rutin, and C-rutin at B3LYP/6-31G(d,p) level and experiment

spectrum for the stable structures of rutin and A-rutin, B-rutin, and C-rutin at B3LYP/6-31G(d,p) level.

The interaction energies for the MARs with rutin are shown in Table 2. The A-rutin, B-rutin, and C-rutin are $8.92,9.75$, and $11.21 \mathrm{kcal} \mathrm{mol}^{-1}$ stable than the corresponding preliminary reactants from the B3LYP/PCM/6$31 \mathrm{G}(\mathrm{d}, \mathrm{p})$ calculations in water. The trend of the interaction energies for the MAR is A-rutin (amino group) $<$ B-rutin (hydroxyl group) $<\mathrm{C}$-rutin (carboxyl group). That is to say, forming hydrogen-bonding for one molecule MAR with carboxyl group is more stable than the amino and hydroxyl groups. We plotted the frontier molecular orbitals (HOMO and LUMO) for rutin and the adsorption complexes in Fig. 5. The frontier orbital energy level $\left(\Delta E_{\mathrm{g}}=\right.$ $\left.E_{\mathrm{LUMO}}-E_{\mathrm{HOMO}}\right)$ of rutin is $0.10552 \mathrm{eV}$, while the $\Delta E_{\mathrm{g}}$ of A-rutin, B-rutin, and C-rutin is 0.10031, 0.10334, and $0.10560 \mathrm{eV}$, respectively. Especially, the $\Delta E_{\mathrm{g}}$ of A-rutin and B-rutin is lower than rutin because of the MAR. The adsorption reaction occurs more easily for amino and hydroxyl groups. 

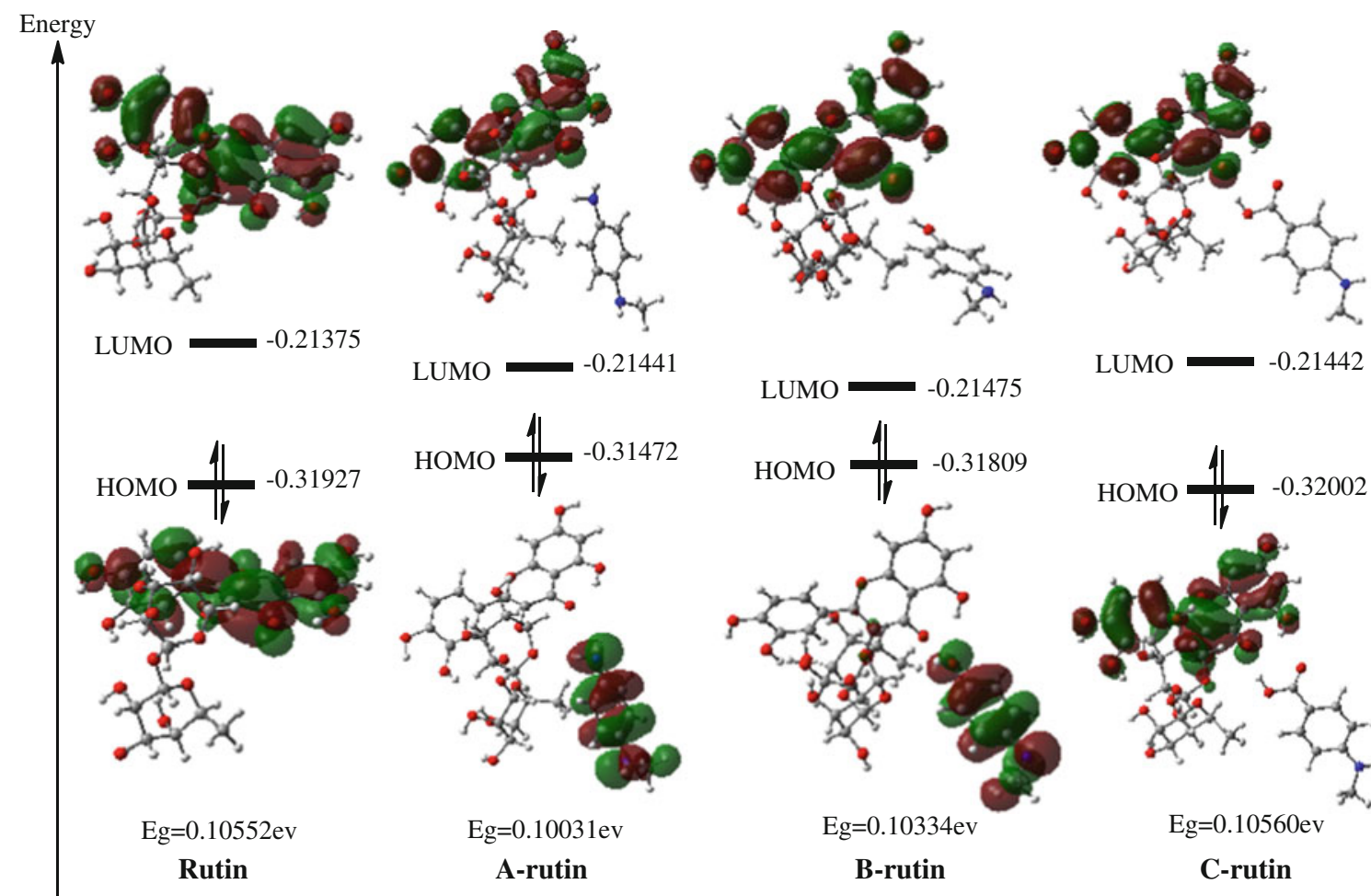

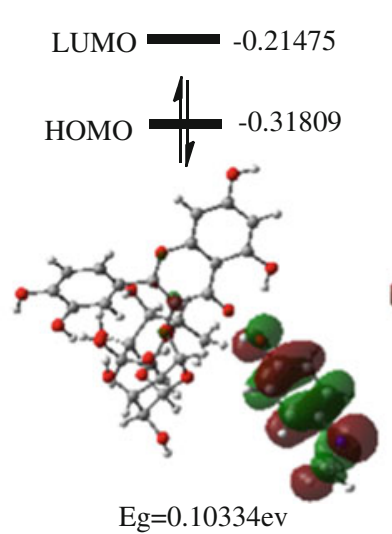

B-rutin
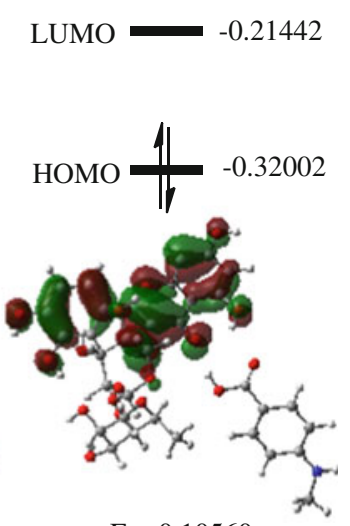

$\mathrm{Eg}=0.10560 \mathrm{ev}$

C-rutin

Fig. 5 Spatial plots of the frontier molecular orbitals calculated for rutin, A-rutin, B-rutin, and C-rutin. The orbital energies are given in eV

Adsorption mechanism of rutin

onto $\left(p-\left(\mathrm{CH}_{3} \mathrm{NH}\right) \mathrm{PhNH}_{2}\right)_{n}(n=1-3)$

The adsorption experimental results show that the greater adsorption capacity has been found for the MAR with amino group. This MAR contains numerous amino groups, which could form many of hydrogen-bonding with a rutin molecule. Here, we present a detailed computational investigation of the rutin by explicitly coordinating one, two, and three the resin with amino group to the $\mathrm{O}$ and $\mathrm{H}$ atoms. Figure 2 depicts the optimized geometries found for rutin with $\left(p-\left(\mathrm{CH}_{3} \mathrm{NH}\right) \mathrm{PhNH}_{2}\right)_{n}(n=1-3, \mathrm{~A}$-rutin to A3-rutin), and the key geometrical parameters are given in Table 1. In A2-rutin and $\mathrm{A} 3$-rutin, the $\mathrm{N}$ atom of resin attack to the $\mathrm{H}$ atom of rutin and the $\mathrm{H}$ atom of amino group add to $\mathrm{O}$ atom of rutin through forming hydrogen-bonding. The new $\mathrm{N}-\mathrm{H}$ and $\mathrm{O}-\mathrm{H}$ bond lengths are 2.017-3.008 $\AA$ in A2-rutin and A3-rutin. Examination of Table 2 shows the two $p-\left(\mathrm{CH}_{3} \mathrm{NH}\right) \mathrm{PhNH}_{2}$ molecules adsorption for rutin has a interaction energy of $9.95 \mathrm{kcal} \mathrm{mol}^{-1}$ relative to the starting materials, which is decreased significantly by $1.03 \mathrm{kcal} \mathrm{mol}^{-1}$ compared to the corresponding one $p-\left(\mathrm{CH}_{3} \mathrm{NH}\right) \mathrm{PhNH}_{2}$ adsorption. While the interaction energy for three $p-\left(\mathrm{CH}_{3} \mathrm{NH}\right) \mathrm{PhNH}_{2}$ becomes $10.69 \mathrm{kcal} \mathrm{mol}^{-1}$ and this is decreased by $0.74 \mathrm{kcal} \mathrm{mol}^{-1}$ compared to the analogous energy two $p-\left(\mathrm{CH}_{3} \mathrm{NH}\right) \mathrm{PhNH}_{2}$ $\left(9.95 \mathrm{kcal} \mathrm{mol}^{-1}\right)$. The adsorption complexes becomes more stable as the number of $p-\left(\mathrm{CH}_{3} \mathrm{NH}\right) \mathrm{PhNH}_{2}$ goes from $n=1$ to $n=3$. Upon saturation of the rutin by coordination of $p$ - $\left(\mathrm{CH}_{3} \mathrm{NH}\right) \mathrm{PhNH}_{2}$ molecules one by one, the interaction energy of species would become relatively constant.

Systematic comparisons of experiment for the adsorption behavior

Figure 4 shows the IR spectra of the resins A (PPDA) and $\mathrm{C}$ (PANB). In the spectrum of A, there is an absorption band in the vicinity of $3374.3 \mathrm{~cm}^{-1}$ that belongs to the stretching vibrations of the $\mathrm{N}-\mathrm{H}$ bond. In addition, the $\mathrm{C}-\mathrm{N}$ stretching of the benzene ring and $\mathrm{NH}$ group are shown to be at $1,024 \mathrm{~cm}^{-1}$. Two other characteristic peaks related to the $\mathrm{C}=\mathrm{C}$ stretching of phenyl group at 1605 and $1495 \mathrm{~cm}^{-1}$ are much stronger than before reacting, and another two bands at 812.3 and $694 \mathrm{~cm}^{-1}$, which involve $\mathrm{C}-\mathrm{H}$ out of bending of $\mathrm{CH}$ group for mono-substitution of benzene. For the IR spectrum of $p$-aminobenzoic acid modified resin. A moderate $\mathrm{C}=\mathrm{O}$ stretching band involved in formaldehyde carbonyl groups comes forth at $1698.4 \mathrm{~cm}^{-1}$. Finally, a weak absorption band appears at $3394.5 \mathrm{~cm}^{-1}$, and this band is related to $\mathrm{O}-\mathrm{H}$ stretching of hydroxyl hydrogen .

Comparing the adsorption capacity of flavonoids (rutin) on the three adsorbents by experiment method, we can understand that they follow the order $\mathrm{A}\left(-\mathrm{NH}_{2}\right)>\mathrm{B}$ $(-\mathrm{OH})>\mathrm{C}(-\mathrm{COOH})$, and the MARs with amino group has 
the highest equilibrium adsorption capacity at the equilibrium concentration. From Table 2, we observed that the computed interaction energies for the adsorption is given in the following order, $p-\left(\mathrm{CH}_{3} \mathrm{NH}\right) \mathrm{PhCOOH}>p-\left(\mathrm{CH}_{3} \mathrm{NH}\right)$ $\mathrm{PhOH}>p-\left(\mathrm{CH}_{3} \mathrm{NH}\right) \mathrm{PhNH}_{2}$. The result shows that the hydrogen-bonding of $p$ - $\left(\mathrm{CH}_{3} \mathrm{NH}\right) \mathrm{PhCOOH}$ with rutin is the more stable compared to $p-\left(\mathrm{CH}_{3} \mathrm{NH}\right) \mathrm{PhOH}$ and $p$ - $\left(\mathrm{CH}_{3} \mathrm{NH}\right) \mathrm{PhNH}_{2}$. While the adsorption capacity has been investigated including of many of the factors controlling except for functional group, such as pore diameter, BET surface area, pore volume, particle size, group amount, temperature, etc. In this article, we mainly present a detailed DFT computational investigation of the hydrogen-bonding adsorption mechanism for rutin onto $p-\left(\mathrm{CH}_{3} \mathrm{NH}\right) \mathrm{PhL}$ $\left(\mathrm{L}=\mathrm{NH}_{2}, \mathrm{OH}, \mathrm{COOH}\right)$.

\section{Conclusion}

In this article, we have carried out a theoretical investigation at the DFT (B3LYP) level for the adsorption mechanism of rutin onto a series of MARs functionalized with amino, hydroxyl, and carboxyl groups. According to our calculations, the adsorption mechanism of rutin onto the resin is based on hydrogen-bonding. The interaction energies for adsorption complexes are 8.92-11.21 kcal mol ${ }^{-1}$, and C-rutin is the more stable than A-rutin and B-rutin. The adsorption experiments show that adsorption capacity of A-rutin is the highest. We present a detailed computational investigation of the rutin by explicitly coordinating one, two, and three A-rutin to the $\mathrm{O}$ and $\mathrm{H}$ atoms of rutin. Upon saturation of the rutin by coordination of $p-\left(\mathrm{CH}_{3} \mathrm{NH}\right) \mathrm{PhNH}_{2}$ molecules one by one, the adsorption complexes becomes more stable. Our computational results are in good explanation for the experimental observations, which has comprehensive ramifications for the adsorbent synthesize, adsorption experimental design, and practical application.

Acknowledgments This research project was financially supported by the Hundred Talents Program of the Chinese Academy of Sciences (CAS) and the National Natural Sciences Foundation of China (NSFC, No. 20974116).

Open Access This article is distributed under the terms of the Creative Commons Attribution License which permits any use, distribution, and reproduction in any medium, provided the original author(s) and the source are credited.

\section{References}

1. Tsyurupa MP, Maslova LA, Andreeva AI, Mrachkovskaya TA, Davankov VA (1995) React Polym 25:69

2. Malik DJ, Warwick GL, Venturi M, Streat M, Hellgardt K, Hoenich N, Dale JA (2004) Biomaterials 25:2933

3. Lahari C, Jasti LS, Fadnavis NW, Sontakke K, Ingavle G, Deokar S, Ponrathnam S (2010) Langmuir 26:1096

4. Valderrama C, Gamisans X, Heras X, Farran A, Cortina JL (2008) J Hazard Mater 157:386

5. Du XL, Yuan QP, Li Y, Zhou HH (2008) Chem Eng Technol 31:87

6. Ma CY, Tao GJ, Tang J, Lou ZX, Wang HX, Gu XH, Hu LM, Yin ML (2009) Sep Purif Technol 69:22

7. Liu YF, Liu JX, Chen XF, Liu YW, Di DL (2010) Food Chem 123:1027

8. Oberholzer MR, Lenhoff AM (1999) Langmuir 15:3905

9. Huang HH, Huang KL, Liu SQ, Luo Q, Shi SY (2008) J Colloid Interface Sci 317:434

10. Gao WH, Butler D, Tomasko DL (2004) Langmuir 20:8083

11. Li AM, Zhang QX, Chen JL, Fei ZG, Chao L, Li WX (2001) React Funct Polym 49:225

12. Hawthorne SB, Poppendieck DG, Grabanski CB, Loehr RC (2001) Environ Sci Technol 35:4577

13. Chu BS, Baharin BS, Man YBC, Quek SY (2004) J Food Eng 64:1

14. Lou S, Chen ZB, Liu YF, Ye HL, Di DL (2011) Langmuir 27:9314

15. Becke AD (1993) J Chem Phys 98:5648

16. Miehlich B, Savin A, Stoll H, Preuss H (1989) Chem Phys Lett 157:200

17. Rassolov VA, Ratner MA, Pople JA, Redfern PC, Curtiss LA (2001) J Comput Chem 22:976

18. Rassolov VA, Pople JA, Ratner MA, Windus TL (1998) J Chem Phys 109:1223

19. Tomasi J, Persico M (1994) Chem Rev 94:2027

20. Mineva T, Russo N, Sicilia E (1998) J Comput Chem 19:290

21. Cossi M, Scalmani G, Rega N, Barone V (2002) J Chem Phys 117:43

22. Frisch MJ, Trucks GW, Schlegel HB, Scuseria GE, Robb MA, Cheeseman JR, Zakrzewfki VG, Montgomery JA, Stratmann RE, Burant JC, Dapprich S, Millam JM, Daniels AD, Kudin KN, Strain MC, Farkas O, Tomasi J, Barone V, Cossi M, Cammi R, Mennucci B, Pomelli C, Adamo C, Clifford F, Ochterski J, Petersson GA, Ayala PY, Cui Q, Morokuma K, Malick DK, Rabuck $\mathrm{AD}$, Raghavachari K, Foresman JB, Cioslowski J, Ortiz JV, Stefanov BB, Liu G, Liashenko A, Piskorz P, Komaromi I, Gomperts R, Martin RL, Fox DJ, Keith T, Al-Laham MA, Peng CY, Nanayakkara A, Gonzalez C, Challacombe M, Gill PMW, Johnson BG, Chen W, Wong MW, Andres JL, Head-Gordon M, Replogle ES, Pople JA (2004) Gaussian 03, revision E.01. Gaussian, Inc, Pittsburgh 